\title{
A social network analysis of internally displaced communities in northeast Nigeria: potential conflicts with host communities in the Lake Chad region
}

\author{
Frederic Noel Kamta $\mathbb{D} \cdot$ Jürgen Scheffran
}

Accepted: 25 August 2021 / Published online: 3 September 2021

(C) The Author(s) 2021

\begin{abstract}
In this study, we aim to analyze social networks in which internally displaced persons (IDPs) are involved in northeast Nigeria, after they have been displaced by the insurgency of the Boko Haram group. While IDPs usually resettle in camps operated by the government, contacts with host communities are common. We further analyze the potential that such contacts may lead to conflicts between IDPs and their host communities in the Lake Chad region. Data for this study were collected by interviewing IDPs in the Bakassi IDP camp in Maiduguri and by interviewing members of the host community in Maiduguri in close proximity to the Bakassi IDP camp. A Social Network Analysis approach was used to analyze the data, by constructing social network graphs and computing network attributes, mainly the betweenness centrality of actors. The results of the study show on the one hand a mixture of friendly and conflicting relationships between IDPs and the host community from the IDPs' perspective, and on the other hand, only few contacts between members of the host community and
\end{abstract}

F. N. Kamta $(\bowtie) \cdot$ J. Scheffran

Research Group Climate Change and Security (CLISEC), Institute of Geography, Center for Earth System Research and Sustainability (CEN), University of Hamburg, Hamburg, Germany

e-mail: frederickamta1@yahoo.fr

F. N. Kamta

School of Integrated Climate System Sciences (SICSS), University of Hamburg, Hamburg, Germany
IDPs in the Bakassi IDP camp, from the host community's perspective. The analysis suggests that in the context of conflict present in the Lake Chad region, IDPs and members of the host community mainly use closed networks, to keep available resources and economic opportunities within their communities. We recommend a better service delivery to IDPs but also to members of the host communities who feel neglected as more attention is given to IDPs with the distribution of humanitarian aid.

Keywords IDP $\cdot$ Host community $\cdot$ Conflict $\cdot$ Social networks $\cdot$ Nigeria $\cdot$ Maiduguri $\cdot$ Lake Chad

\section{Introduction}

Over the past decade, migration crises have evolved in various parts of the world. Europe as a whole has seen the incoming of millions of migrants, mainly from the Syrian Arab Republic, Iraq and Afghanistan, but also from Africa through the Mediterranean (GiménezGómez et al., 2019; McAuliffe et al., 2019). A significant increase of migration movements have also been observed in the Americas, with half of the migration directed towards the United States of America (OECD, 2016). Migration between African countries has also increased and it is estimated that in 2019, over 21 million Africans were living in another 
African country, a significant increase from 2015, when around 18.5 million Africans were estimated to be migrants within the continent (McAuliffe et al., 2019). Among the regions of Africa where high numbers of refugees have been observed, is the Lake Chad Basin region. To better understand the geographical patterns of migration, it is essential to first understand the main push factors of migration, or the conditions under which people are prone to migrate.

In the context of African migration, many migrants stay within the borders of their countries, therefore becoming Internally Displaced Persons (IDPs), having a different status than refugees under international law. Article 1A (2) of the 1951 Refugee Convention defines a refugee as a person who: "owing to wellfounded fear of persecution for reasons of race, religion, nationality, membership of a particular social group or political opinion, is outside the country of his nationality and is unable or, owing to such fear, is unwilling to avail himself of the protection of that country; or who, not having a nationality and being outside the country of his former habitual residence as a result of such events, is unable or, owing to such fear, is unwilling to return to it" (UNGA, 1951: 152). In contrast, the Guiding Principles on Internal Displacement defines IDPs as "Persons or groups of persons who have been forced or obliged to flee or to leave their homes or places of habitual residence, in particular as a result of or in order to avoid the effects of armed conflict, situations of generalized violence, violations of human rights or natural or human-made disasters, and who have not crossed an internationally recognized state border" (UNHCR, 1998: 5).

Northeast Nigeria has seen increasing numbers of IDPs in the main cities of the region, in response to the violence perpetrated by the insurgency of the islamist group Boko Haram (Kamta et al., 2020a). Villages in northeast Nigeria in the states of Adamawa, Bauchi, Borno, Gombe, Taraba, and Yobe are severely hit by the Islamist insurgency of Boko Haram (Jacob et al., 2016). Displaced persons mainly seek refuge in host communities and IDP camps operated by the Nigerian government in urban centers in the region. As of 2016, the Boko Haram insurgency was considered to be the greatest single cause of displacements in the Lake Chad Basin with over 2.5 million people leaving their homes, becoming refugees and IDPs (Beltramo \& Rossiasco, 2016). The insurgency in this region is however not the only cause of migration.
Environmental factors have also been studied for their potential role on migration in the Lake Chad Basin region (Akubor, 2017; Zieba et al., 2017; Freeman, 2017; Rudincova, 2017; Kamta et al., 2020b). In this region where resources are scarce due to desertification and prolonged droughts, migration may lead to high concentration of persons in certain areas of the region, therefore exerting more pressure on the resources. In this context, the competition for resources may lead to tensions between host communities and IDPs or even between different groups of IDPs. It is therefore necessary to understand the nature and dynamics of the relationships between IDPs within their settlements, and between IDPs and host communities in the region.

In the context of insecurity and resource scarcity in northeast Nigeria, a promising approach to study the relationships between IDPs and host communities is Social Network Analysis (SNA) which is commonly used to understand social connections and behaviors in studies related to conflict analysis, resource management and many more (Mertens et al., 2015; Ngaruiya \& Scheffran, 2016; Mincer and NiewiadomskaSzynkiewicz, 2012). A social network illustrates a set of nodes (actors) and their connections to study social interactions and patterns that would otherwise go unnoticed (Sridevi \& Arun, 2015). SNA may not be a completely new tool, but it has seen little theoretical or empirical establishment. More recently, researchers from social and natural sciences have proposed an interdisciplinary effort to establish social network theory, following the trend of information visualization (Havig et al, 2012). In this study, we apply SNA principles to IDP communities in the Bakassi IDP camp located in Maiduguri, northeast Nigeria, to understand how they connect with the host community in Maiduguri and between themselves. SNA allows this study to evaluate the potential of conflict between IDPs and host communities. The same concept is also applied to members of the host community to understand the nature of their relationships with IDPs. This study assesses the presence or absence of a relationship between IDPs and the host community, and determines the centrality of the actors, hence informing how relevant they are in the network of relationships. The current study will address the following questions: What are the networks in which IDPs in Maiduguri are involved? What is the potential of 
conflict between IDPs and host communities in Maiduguri?

To address these issues and answer the research questions, section one of this paper provides an introduction of conflict and migration with a focus on northeast Nigeria. In section two, a literature review of key sources in the area of migration and a description of the relationship between the sources is presented. Section three develops the theoretical framework used in the paper and its connection to SNA. Thereafter, section four presents the methods used to collect and analyze the data, and section five the results of the study. Finally, section six discusses the results and general conclusion of the study while the implications are given in section seven.

\section{Theoretical considerations of human migration in the literature}

Human migration was observed and explained by various theories and fields of research, including anthropology, history, geography, biological, health, economic and social sciences, each with a different perspective (Lucassen et al., 2010). Early concepts emphasized demographic and geographical features as drivers of migration which laid the groundwork for future theoretical models on migration (e.g. McNeill, 1984; Ravenstein, 1889). A common approach is to look at migration as a process mainly driven by economic motivations. The European Asylum Support Office (EASO, 2016) for example, estimates migration based on early neoclassical economic theories, assuming that individuals act rationally to maximize utility and would be expected to move when the benefit of moving (or the cost of staying) generate the highest financial return on labor. Economic migration may also be driven by the high demand of skilled workers in some countries, as is the case for intra migration between east and southern Africa (McAuliffe et al., 2019).

Widely used is the theory of push-pull factors motivating migration. This theory has regularly been used as an analytical framework for migration research (e.g. Antwi-Boateng, 2017; Beck et al., 2017; Obi-Ani \& Osiani, 2020). A set of push factors are related to the sending area of the migrants, while pull factors are related to the receiving area. Some of the push factors identified by Holobinko (2012) include but are not limited to lack of jobs or employment opportunities; adverse environmental conditions such as famine and natural disasters; poor infrastructure, including inadequate medical care; lack of political or religious freedom. Holobinko (2012) also identified some pull factors including increased job opportunities; better living conditions; freedom of speech; improved infrastructure and security. It can be anticipated that when pull factors are present within the same region or country, migrants may settle without crossing an international border, hence the notion of internal migration. Alonso (1986), sees internal migration as an equilibrating mechanism that reduces differences in unemployment and per capita income within the national borders. Given the strong role that economic factors play on migration, interaction or even competition between migrants and local residents can be anticipated.

Socioeconomic push factors are ranked high by many scholars and organizations. The European Asylum Support Office (EASO, 2016) identifies population growth, the decline in rural employment opportunities, economic and technological development as key drivers of migration. Conflict is also cited among other critical aspects of migration (e.g. Kamta et al., 2020b). This includes intractable conflicts, political and communal violence, and peacebuilding setbacks (McAuliffe et al., 2019).

Environmental change and climate change inducing food and water insecurity may also push people to migrate from rural areas to cities, or even abroad (e,g. Bukari et al., 2020; Flavell et al., 2020; Gemenne \& Reuchlin, 2008; Warner \& Afifi, 2014). However, critical perspectives show that environmental change is rarely an isolated driver of migration and needs to be seen in the context of other drivers and conditions (see Sow et al., 2015; Scheffran, 2020). Sow et al. (2014) for example, found that for most rural communities in northern Ghana and northern Benin, mobility was employed as a livelihood strategy when it was most appropriate to do so and often when it could improve livelihood security. Therefore, adaptation measures were suggested in order to reduce youth migration by offering them better environmental conditions (Scheffran et al., 2012).

Besides individual drivers of migration, collective, network, community and social drivers affect migration movements. Piguet (2012) suggested that the processes that lead an individual to migrate in 
response to climate signals are complex unlike simplistic segregation processes theories developed by Schelling (1978), and argued that a much deeper theoretical understanding of the migration decisionmaking process is at stake and more extensive household surveys are needed. Complex dynamic approaches are also adequate to understand the impact of climate change on migration and a promising field in migration studies (Kniveton et al., 2012).

Regarding the impacts of internal migration, a few studies clarified its negative impact on residents' employment and wages (e.g. Boustan et al., 2010; Kleemans \& Magruder, 2017). As a consequence, links have been established between internal migration and violence. Egger (2017) found a significant and positive effect of internal immigration on homicides at municipality level in Brazil. Furthermore, Guéhenno (2016) suggested that refugees create risk factors for new cycles of conflict, generating further refugee flows and that countries that host disproportionately large numbers of refugees without adequate support can be destabilized, exacerbating existing economic, political, and security strains. The assumption we make and that we investigate in the present study is that settlement of IDPs in northeast Nigeria is likely to generate tensions between them and host communities. Based on previous findings on the role of migration in conflict (e.g. Egger, 2017; Guéhenno, 2016) we investigate the nature of the relationships between IDPs and host communities in Maiduguri and the potential that tensions or conflict may erupt between the two groups.

\section{Theoretical framework}

A key issue today for developing countries is internal migration which is complicated by other issues such as conflict and instability, stress on resources and accommodation. One of those issues, which is of major concern is post-displacement conflict between IDPs and host communities, or even between different displaced groups. Scholars have largely failed to converge on the security dimension of migration in developing countries (Mitchell, 2018), which is exacerbated by the homogeneous nature of the communities in Africa. According to Weiner (1992/1993), a homogeneous society, for example, places a higher value on preserving its ethnic character than does a heterogeneous society, therefore, regarding a population influx as a threat to its security. Nigeria is a country with three major ethnic groups (Hausa, Yoruba and Igbo) among which there are over 200 minority groups (Oyedeji, 2017). In such a context, people migrating from one community to a different community are most likely bound to encounter another minority group. In line with the statement by Weiner (1992/1993) above, such an encounter presents potentials for conflict.

According to Ladan (2004), IDPs are persons or groups who have been forcefully moved from their habitual residence to new places within national borders considered relatively safe, as a result of conflict, violations of human rights, generalized violence, natural or manmade disasters. IDPs at the Bakassi camp migrated there from Gwoza, Guzamala, Marte, Monguno and Nganzai. Among these five communities alone, a few tribes were recorded. The Kanuri are largely represented across the region, with several sub-tribes. In Marte, there is a small group of Shoa Arabs, in Gwoza there is the Gwoza tribe, and in Guzamala, Monguno and Nganzai, there are groups belonging to the Kwayam and the Kanembu subtribes. Communities in northeast Nigeria are highly heterogeneous and any migratory movement within the region is likely to involve different tribes or subtribes. The armed conflict between Nigerian military forces and Boko Haram insurgents has been identified as the main push factor for internal migration in the region (see Kamta et al., 2020b).

A definition of conflict may help to understand its relevance for displacement. Being an integral part of human life and an outcome of behaviors (Thakore, 2013), conflicts exist when two or more groups engage in a struggle over values and claims for status, power, and resources in which the aims of the opponents are to neutralize, injure, or eliminate the rivals (Jeong, 2000). Conflict has been thought to arise from opposing interests involving scarce resources and goal divergence and frustration, occurring in mixed-motive relationships where persons have both competitive and cooperative linkages. Competitive linkages produce the conflict, cooperative linkages create the incentives to bargain to reach an agreement (Tjosvold, 2006).

A tool to study social interactions is social network analysis (SNA) which has previously been used in several domains, including natural resources governance or conflict management (Gatewood \& Price, 
2017; Ngaruiya \& Scheffran, 2016). The use of SNA brings together a quantitative and qualitative approach for the integrated analysis of political, economic or social processes in connection to structural and environmental processes (Bodin \& Prell, 2011). Conflict has the potential of breaking social structures in a region (Gatewood \& Price, 2017). As a result of the conflict between Boko Haram insurgents and governmental forces in northeast Nigeria, communities are displaced and forced into new social structures. Such structures in IDP camps or in host communities are often different from those in their home communities where there has been a strong emphasis on the relationships and bonds between people (Smith, 2013). In this study as described in the method section, IDPs from five different communities are hosted in the camp where data were collected. The camp is itself located in a community in Maiduguri. We consider that due to the harsh living conditions in the camp and in the host community as a result of the high poverty level, the competition for survival may result in tensions between members of the five communities that migrated to the camp, or between IDPs and the host community. The SNA approach can assist in establishing how relationships are formed in the IDP camps, between IDPs in the camp and between the IDPs and members of the host communities. The potential of SNA to study the relationship between conflict and internal displacement in northeast Nigeria will be determined in the present study.

\section{Methods}

Study area

Data were collected in the Bakassi IDP camp in Maiduguri and in the adjacent local community that hosts the Bakassi IDP camp (Fig. 1). Respondents in the Bakassi IDP camp were from Guzamala, Gwoza, Marte, Monguno and Nganzai, five LGAs from northeast Nigeria. Members of these communities migrated to the camp after their communities were subject to attacks by the Boko Haram terrorist group. At the time of data collection, Marte was the largest community in the camp with 13,600 members, followed by Gwoza with 12,000 members, Monguno with 9700 members, Guzamala with 3000 members, and Nganzai with 750 members. Among the 39,000
IDPs in the Bakassi IDP camp, $49.3 \%$ of them were young boys and girls, and $50.7 \%$ were adults. Among the adult population of the camp, 204 IDPs were interviewed and distributed as follows: 60 from Gwoza, 43 from Marte, 41 from Monguno, 22 from Nganzai and 38 from Guzamala. Such interviews were semi-structured with close ended and open ended questions.

Members of the host community adjacent to the IDP camp were also interviewed with close ended and open ended questions. A total of 100 members of the host community participated in the interview. According to the World Population Review (WPR, 2021), the total population size of Maiduguri was 772,000 in 2019. The population size of the community where interviews were conducted is unknown, but can be estimated to be between 700 and 1000 inhabitants. Figure 1 shows the IDP camp and the local community where interviews were conducted.

IDP and host community respondents in this study were males and females between 18 and 80 years old and mostly practiced farming, business or other income generating activities such as tailoring. Table 1 presents the bio-demographic data of the respondents in the IDP camp as well as the host community.

\section{Data collection}

Data were collected by means of semi-structured interviews with close ended and open ended questions. Respondents were asked on a scale from 1 to 5 to evaluate the level of their relationships with a group of actors or with some institutions. On this scale, 1 and 2 represent a negative or conflicting relationship, 3 is a neutral relationship while 4 and 5 represent a positive or friendly relationship. Each respondent in the camp was asked to rate their relationship with IDPs from the same LGA, with IDPs from other LGAs within the Bakassi IDP camp, with members of the host community, and with IDPs from other IDP camps in and around Maiduguri. In the host community, respondents were asked to indicate if they have had any contacts with IDPs located in the Bakassi IDP camp, or with IDPs from any other IDP camps in and around Maiduguri.

In addition to SNA data, questions related to the potential of future conflicts between IDPs and the host community were asked both in the camp and in the host community. Qualitative interviews with experts 


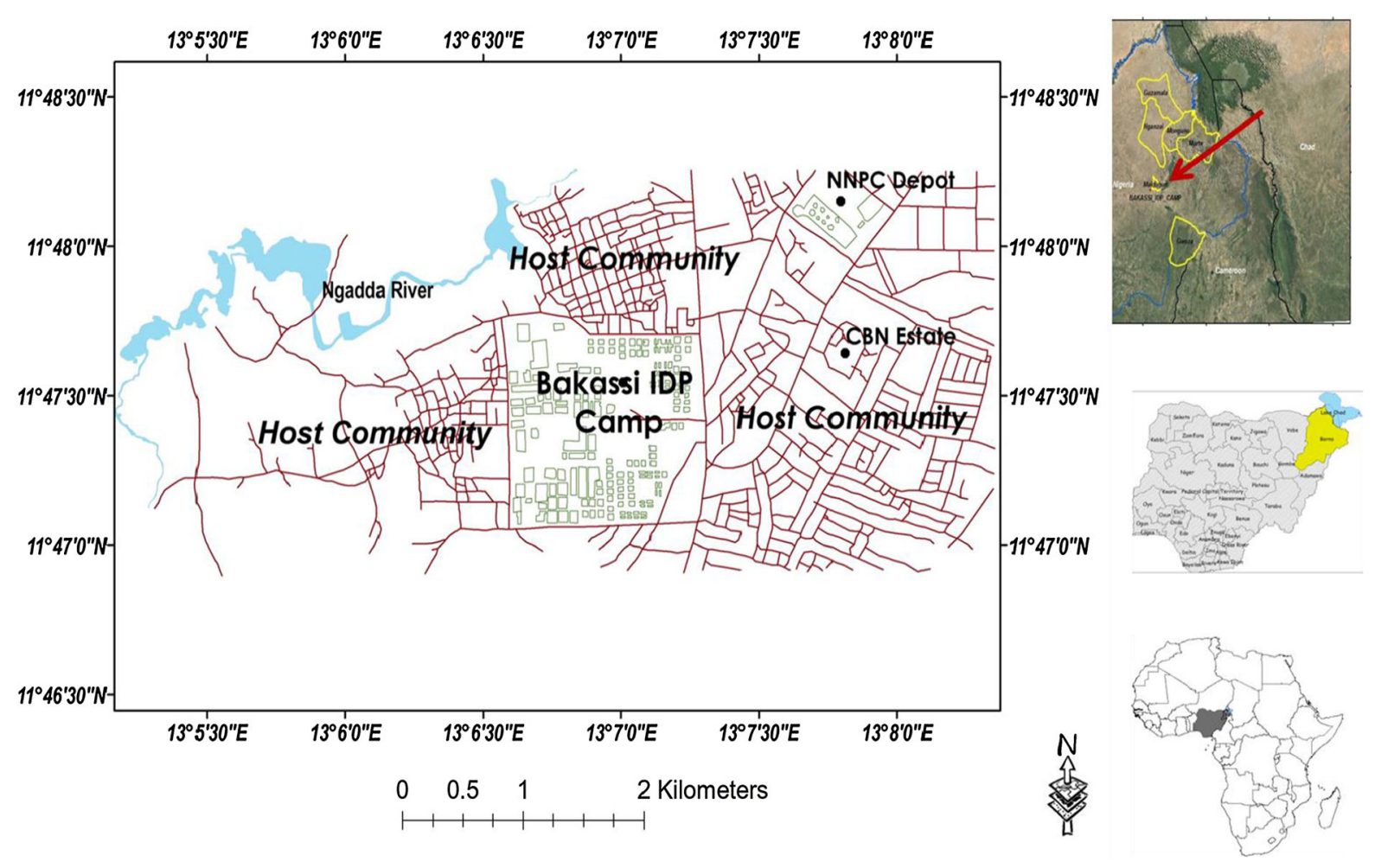

Fig. 1 Study area showing the Bakassi IDP camp and the host community

Table 1 Bio-demographic data of all 304 respondents

\begin{tabular}{|c|c|c|c|c|c|c|c|}
\hline \multirow[t]{2}{*}{ Community } & \multicolumn{2}{|c|}{ Gender } & \multicolumn{3}{|c|}{ Age group } & \multicolumn{2}{|c|}{ Occupation (before displacement } \\
\hline & $\begin{array}{l}\text { Male } \\
(\%)\end{array}$ & $\begin{array}{l}\text { Female } \\
(\%)\end{array}$ & $\begin{array}{l}\text { Under } \\
30(\%)\end{array}$ & $\begin{array}{l}30-50 \\
(\%)\end{array}$ & $\begin{array}{l}\text { Above } \\
50(\%)\end{array}$ & Farming $(\%)$ & $\begin{array}{l}\text { Business and other } \\
\text { activities }(\%)\end{array}$ \\
\hline Gwoza & 15 & 85 & 27 & 58 & 15 & 77 & 45 \\
\hline Marte & 53 & 47 & 7 & 49 & 44 & 91 & 44 \\
\hline Monguno & 49 & 51 & 9 & 80 & 11 & 83 & 34 \\
\hline Nganzei & 27 & 73 & 18 & 68 & 4 & 86 & 32 \\
\hline Gouzamala & 53 & 47 & 26 & 45 & 29 & 95 & 18 \\
\hline Host community & 70 & 30 & 24 & 53 & 23 & 50 & 50 \\
\hline
\end{tabular}

were also conducted in Abuja, the Federal Capital Territory of Nigeria and questions were asked in relation to the potential of conflict between IDPs from different communities, but mostly between IDPs and host communities. Experts that were interviewed worked on various issues related to IDPs and host communities in Borno state, but because of the safety conditions in Borno, they were mostly located in Abuja and often conducted field missions in Maiduguri. Furthermore, interviewing these experts in Abuja limited the time spent in Maiduguri by the research team, hence limiting exposure to conflict. Table 2 indicates the position occupied by experts that were interviewed and their respective organizations.

Data analysis

To analyze the data in this study, a mixture of qualitative and quantitative data analysis methods was used. According to Philip (1997), the use of mixed 
Table 2 Positions and thematic expertise of experts interviewed

\begin{tabular}{|c|c|c|}
\hline Expert organization & Position occupied & Thematic expertise \\
\hline The Institute of Peace and Conflict Resolution (IPCR) & $\begin{array}{l}\text { Research Officer and Legal } \\
\text { Practitioner }\end{array}$ & Defiance and Security \\
\hline The Institute of Peace and Conflict Resolution (IPCR) & Chief Research Fellow & $\begin{array}{l}\text { Conflict, Security and } \\
\text { Development }\end{array}$ \\
\hline $\begin{array}{l}\text { The Federal Ministry of Environment, Department of Climate } \\
\text { Change }\end{array}$ & Chief Scientific Officer & Climate Change and Society \\
\hline $\begin{array}{l}\text { The Federal Ministry of Environment, Department of Climate } \\
\text { Change }\end{array}$ & Scientific Officer & $\begin{array}{l}\text { Vulnerability and } \\
\text { Adaptation }\end{array}$ \\
\hline Federal Ministry of Labour & Assistant Chief Labor Officer & $\begin{array}{l}\text { International Labor } \\
\text { Migration }\end{array}$ \\
\hline $\begin{array}{l}\text { National Commission for Refugees, Migrants and Internally } \\
\text { Displaced Persons (NCFRMI) }\end{array}$ & Assistant Director, Migration & $\begin{array}{l}\text { Migration and Internal } \\
\text { Displacements }\end{array}$ \\
\hline $\begin{array}{l}\text { National Commission for Refugees, Migrants and Internally } \\
\text { Displaced Persons (NCFRMI) }\end{array}$ & Migration Governance Expert & $\begin{array}{l}\text { Migration and Internal } \\
\text { Displacements }\end{array}$ \\
\hline United Nations High Commissioner for Refugees & Senior Protection Assistant & $\begin{array}{l}\text { Human Rights and } \\
\text { Vulnerability }\end{array}$ \\
\hline
\end{tabular}

methods helps to minimize the risk of generating erroneous findings and may also allow a broader range of issues to be addressed during the course of conducting a research project than would be possible if exclusive use of either quantitative or qualitative methods had been made. The choice of SNA in this study is essential as it is the only method that allows a proper visualization of connections between IDPs and host communities. The use of other methods such as agent based modeling has been widely used to study relationships between humans and their natural environment, and also in the case of community interactions, but is limited when it comes to human-human relationships. The use of SNA was then found to be an appropriate tool to study relationships between IDPs and their host communities.

Philip (1997) further explains that the choice of the multi-methods approach is an obvious one in contemporary human geography influenced by postmodernism and poststructuralism. Results of the quantitative analysis in this study were confirmed by the qualitative analysis of the experts' interviews. Both methods were therefore used in a complementary manner to properly address the nature of the relationships between IDPs and host communities and the potential of tensions or conflict between both groups in Maiduguri.

\section{Betweenness centrality}

Social network data were analyzed using the software packages Ucinet (Borgatti et al., 2002), and Netdraw (Borgatti, 2002) which were used to represent the network including actors and ties. Ucinet was also used to calculate network attributes such as betweenness centrality. The betweenness centrality index counts the number of network pathways passing through an actor and is used to measure how much potential control an actor has over disseminating accurate and relevant information across the community network (Ngaruiya \& Scheffran, 2016). For a one mode network, it can be obtained using Eq. (1).

$C_{B}(k)=\sum_{\mathrm{i} \neq \mathrm{j} \neq \mathrm{k}} \frac{\partial \mathrm{ikj}}{\partial \mathrm{ij}}$,

In this equation, $C_{B}(k)$ is the betweenness centrality of actor $\mathrm{k}$, oikj is the number of paths linking actors $\mathrm{i}$ and $\mathrm{j}$ that pass through actor $\mathrm{k}$, and $\mathrm{\partial ij}$ is the number of paths linking actor $\mathrm{i}$ and $\mathrm{j}$. More basically, Brandes (2001) suggests that betweenness centrality is traditionally determined by computing the length and number of shortest paths between all pairs and by summing all pair-dependencies. The definition of betweenness centrality is based on the assumption that 
interactions between two nonadjacent actors might depend on other actors, especially the actors who lie on the path between the two (Wasserman \& Faust, 1994). Mode refers to a class of actors. In this study the first mode is made of single actors and the second mode is made of groups of actors such as Host community, IDPs from the same LGA etc.

The use of SNA allows us to understand the position of actors within the network. This will highlight the centrality of certain actors, those that play key roles in the network. In many social network applications, the main objective of data analysis is to identify the most important actors in a network (Mincer and Niewiadomska-Szynkiewicz, 2012). A network node according to Mincer and Niewiadomska-Szynkiewicz (2012) is considered to be a prominent one, if it is extensively involved in relationships with other nodes that form a social network. Moreover, the importance of a node relies on the number of prominent nodes that are connected to this node.

Centrality of a node $\mathrm{k}$ is defined as the share of times that a node i needs this node (whose centrality is being measured) in order to reach a node $j$ via the shortest path. Specifically, if $g_{i j}$ is the number of geodesic paths from $i$ to $j$, and $g_{i k j}$ is the number of these geodesics that pass through node $\mathrm{k}$, then the betweenness centrality of node $\mathrm{k}$ is given by Eq. (1) above (Borgatti, 2005). Stated in plain language, betweenness basically counts the number of geodesic paths that pass through a node $\mathrm{k}$ (Wasserman and Faust, 1994; Borgatti, 2005). Freeman (1979) also defines betweenness centrality as a measurement based upon the frequency with which a point falls between pairs of other points on the shortest or geodesic paths connecting them.

SNA data in the present study form a 2-mode matrix. For a 2-mode matrix, there can be two different approaches. The first approach is a unimodal approach to the 2-mode matrix. This approach converts the data into a 1-mode matrix. Such an approach is appropriate when the analytical interest focuses primarily on just one of the modes (Borgatti, 2009). The second approach is a bimodal analysis of the 2-mode matrix. In this approach, both modes are analyzed simultaneously. The data in this approach represent relations between two sets of nodes, forming a bipartite graph $\mathrm{GB}(\mathrm{V} 1+\mathrm{V} 2, \mathrm{E})$ in which, for all $\mathrm{u}$ and $\mathrm{v},(\mathrm{u}, \mathrm{v}) \in \mathrm{E}$ if and only if $\mathrm{u}$ and $\mathrm{v}$ belong to different vertex sets (Borgatti, 2009). In this study, we use a bimodal approach of the 2-mode data. This is particularly relevant to the current study because our data includes a mode that consists of individuals (respondents) and their relationship with the second mode which is made of institutions or groups of people.

Betweenness centrality in a bimodal approach of 2mode data

Betweenness centrality is defined above and its value in an ordinary graph is given by the equation above (1). Betweenness is ordinarily normalized by dividing by $(n-1)(n-2)=n^{2}-3 n+2$, which is the maximum betweenness that any node can achieve in a graph with $n$ nodes, which occurs for the node at the center of a star-shaped graph. This maximum is appropriate for bipartite graphs only when one mode has just one node; otherwise we must take account of the sizes of each vertex set. Equation (2) gives the maximums for nodes in each vertex set as a function of the vertex set sizes (Borgatti, 2009).

$$
\begin{aligned}
b_{v 1 \max }= & \frac{1}{2}\left[n_{2}^{2}(s+1)^{2}+n_{2}(s+1)(2 t-s-1)-t(2 s-t+3)\right] \\
& s=\left(n_{1}-1\right) \operatorname{div} n_{2}, t=\left(n_{1}-1\right) \bmod n_{2} \\
b_{v 2 \max }= & \frac{1}{2}\left[n_{1}^{2}(p+1)^{2}+n_{1}(p+1)(2 r-p-1)-r(2 p-r+3)\right] \\
& p=\left(n_{2}-1\right) \operatorname{div} n_{1}, r=\left(n_{1}-1\right) \bmod n_{2}
\end{aligned}
$$

$x$ div $y$ refers to integer division of $x$ by $y$ and $x \bmod y$ refers to the remainder of an integer division of $x$ by $y$.

Betweenness centrality for the bipartite graph can then be normalized by dividing the standard betweenness centrality (1) by the maxima defined above (Borgatti, 2009).

$$
\begin{array}{ll}
b_{i}^{*}=\frac{b_{i}}{b_{v 1 \max }}, \quad \text { for } i \in V_{1} \\
b_{j}^{*}=\frac{b_{j}}{b_{v 2 \max }}, \quad \text { for } j \in V_{2}
\end{array}
$$

\section{Results}

Friendly, neutral and conflicting relationships in the IDP community

The nature of the relationships between different groups of IDPs and between IDPs and host community 
was investigated. Relationships were either friendly, neutral or conflicting. Friendly relationships are indicated by ' 1 ', neutral relationships by ' 0 ' and conflicting relationships by ' -1 '. Table 3 shows in percentage the proportions of IDPs for each LGA according to the nature of their relationships with other groups of IDPs and the host community.

Here, we are more interested in friendly and conflicting relationships; neutral relationships are of least interest. We can observe that relationships between IDPs from the same community or LGA were usually friendly. Relationships between IDPs of a given community and IDPs of a different community were also mostly friendly, but the percentages of conflicting relationships were higher than for relationships between IDPs of the same community.

\section{Relationships between IDPs and host community} as indicated by IDPs

Relationships between IDPs and the host community as indicated by IDPs themselves were mostly neutral. However, a small percentage of the IDPs had friendly relationships with the host community, while a lower percentage (between 0 and 10\%) of the relationships were conflicting. Due to security reasons, many IDPs did not have the possibility to be in contact with the host community, hence they expressed a neutral relationship with the host community. The nature of the relationships between IDPs and host community is shown in Fig. 2.

Relationships between host community and IDPs as indicated by host community members

In the host community, relationships with IDPs were either present (friendly) or absent (neutral). Members of the host community were asked if they had a relationship with IDPs present in the Bakassi IDP camp or with IDPs from other IDP camps within or around Maiduguri. While very few members of the host community reported having a relationship with IDPs in the Bakassi IDP camp that was closer to their community, they all had a relationship with at least one IDP from any other IDP camp in or around Maiduguri. Figure 3 represents a social network graph of the relationships between host community members and IDPs in the Bakassi IDP camp and in any other IDP camps in or around Maiduguri.

Friendly relationships and betweenness centrality of actors at the Bakassi IDP camp

The Ucinet and Netdraw software packages were used to construct the network representation of friendly relationships between IDPs from the same and from other LGAs within the Bakassi IDP camp, between IDPs from the Bakassi IDP camp and members of the
Table 3 Nature of the relationships between IDPs of the same community or LGA (A), between IDPs of different LGAs within the Bakassi IDP camp (B), between IDPs at the Bakassi IDP camp and members of the host community $(\mathrm{C})$ and between IDPs at the Bakassi IDP camp and IDPs in other IDP camps in Maiduguri (D)

\begin{tabular}{lcclcc}
\hline Relationships & Gwoza $(\%)$ & Marte $(\%)$ & Monguno (\%) & Nganzai (\%) & Guzamala (\%) \\
\hline $\begin{array}{l}\text { (A) IDPs from the same LGA } \\
1\end{array}$ & 91.70 & 93 & 92.70 & 100 & 100 \\
0 & 5 & 0 & 7.30 & 0 & 0 \\
-1 & 3.30 & 7 & 0 & 0 & 0 \\
(B) IDPs from different LGAs & & & & \\
1 & 38.30 & 46 & 65.80 & 91 & 94.70 \\
0 & 53.30 & 40 & 24.40 & 4.50 & 5.30 \\
-1 & 8.30 & 14 & 9.80 & 4.50 & 0 \\
(C) Host community & & & & 34.20 \\
1 & 15 & 26 & 22 & 45.40 & 36.80 \\
0 & 68.3 & 44 & 39 & 27.30 & 29 \\
-1 & 16.60 & 30 & 39 & 27.30 & \\
(D) IDPs in other Camps & & & & 23.70 \\
1 & 3.30 & 33 & 36.60 & 22.30 & 5.30 \\
0 & 86.70 & 60 & 61 & 77.70 & 0 \\
-1 & 10 & 7 & 2.40 & & \\
\hline
\end{tabular}


Fig. 2 Nature of the relationships between IDPs and members of the host community from the IDPs perspective, representing case $(\mathrm{C})$ of Table 3

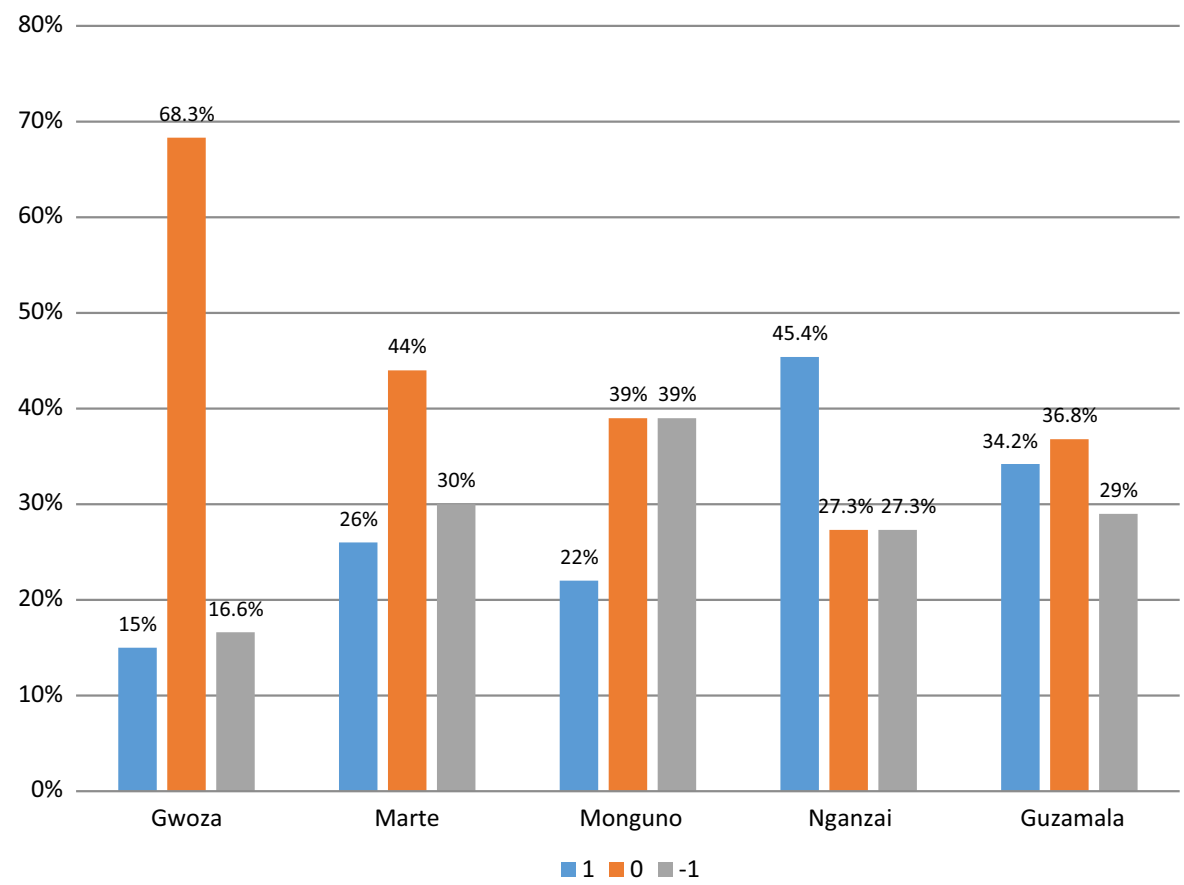

Besides IDP actors present in Table 4, any other agents showed a betweenness centrality value of 0.000 meaning that in terms of conflicting relationships, they were not connected to more than one group of actors.

\section{Discussion}

Results of this study usually illustrate a friendly relationship between IDPs inside the Bakassi IDP camp. On the other hand, relationships with the host community were not so great (see Table 5). Most IDPs reported having a neutral or a conflicting relationship with members of the host community. The previous results are confirmed by the values of betweenness centrality recorded in the case of friendly relationships. Values of betweenness centrality were higher for friendly relationships among IDPs of the same community (0.68), decreasing to 0.185 among IDPs from different communities, to 0.033 between IDPs and the host community and finally to 0.017 between IDPs at the Bakassi camp and IDPs in other camps. From the host community's perspective, the relationship appears friendlier, but still only about $20 \%$ of host community members were connected to IDPs located in the Bakassi IDP camp (see Fig. 3). Most IDPs indicated that they were initially very welcomed by 


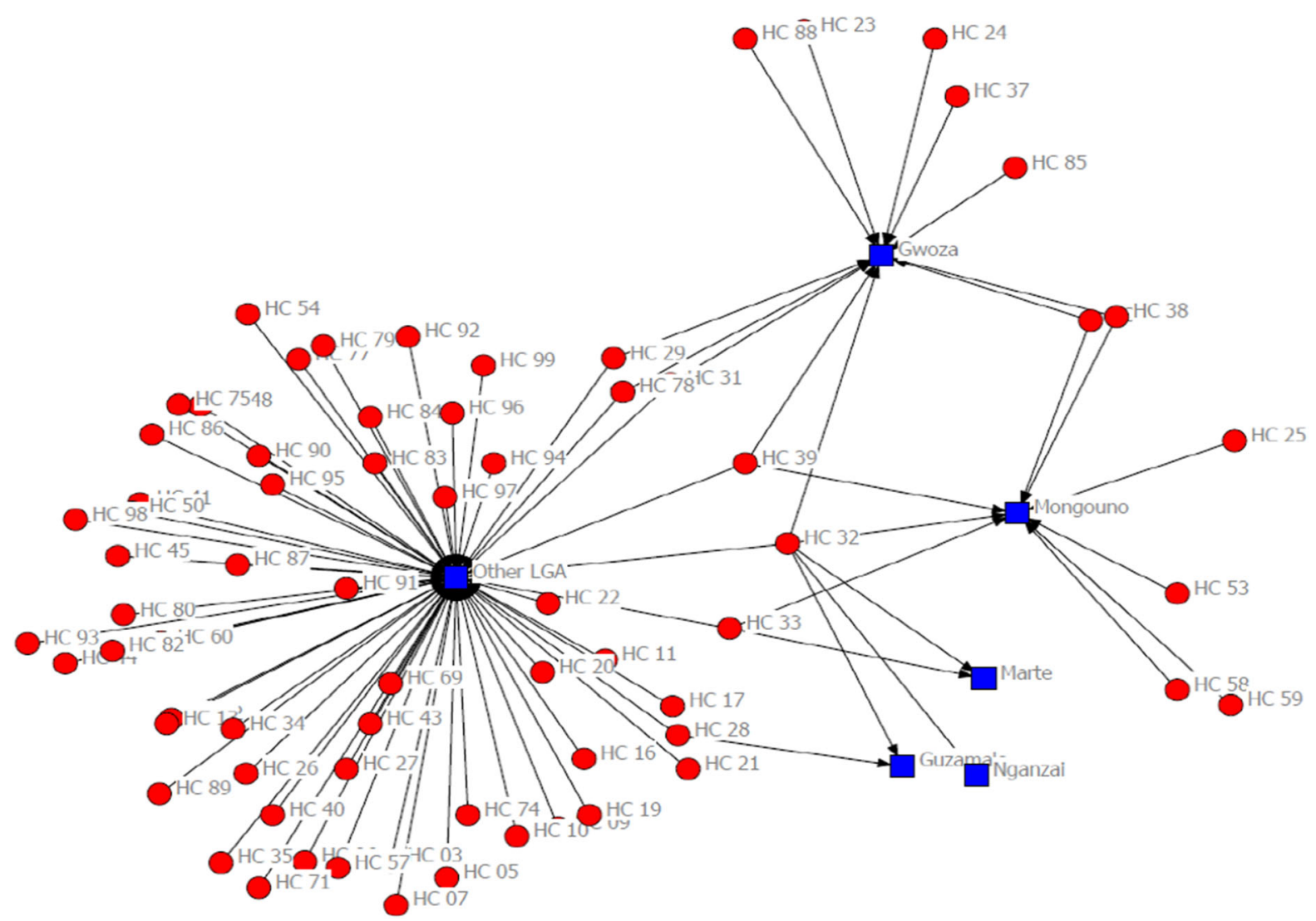

Fig. 3 Social Network Graph of the relationships between members of the host community and IDPs. HC01-HC100 (red dots) represents host community members that were interviewed. 'Other LGA' (blue square) indicates IDPs from other

members of the host community, but the relationship deteriorated with time. A 44 year-old male IDP from Marte for example, stated:

"We usually received visits and gifts from the host community, but now we do not see them anymore and we feel that they do not want us anymore."

Experts mostly believe that the sense of rejection expressed by IDPs may be a result of existing resource constraints in the host community, intensified by the extra pressure brought by IDPs and may in the long run, result in creating animosity and possibly tensions between both groups.

With the supply of humanitarian assistance to IDPs in camps in northeast Nigeria, host communities who are often poor with limited basic services and infrastructures have been largely forgotten besides being
LGAs present at IDP camps other than the Bakassi IDP camp. The other blue squares represents IDPs from Guzamala, Gwoza, Marte Monguno and Nganzai located in the Bakassi IDP camp. (Color figure online)

significantly strained by the presence of IDPs (IOM, 2015; Adeola, 2020). Most IDPs upon arriving in the city are hosted by a relative or friend in the host community (see Davies, 2012). They are later referred to a camp when the host can no longer meet their needs in terms of food and other basic services. This was the experience of most IDPs interviewed in the Bakassi IDP camp. The relationship thereafter tends to become progressively conflicting due to the fact that on the one hand, IDPs feel abandoned by the host community, and on the other hand, the host community feels that IDPs get more attention than them. Such was seen by an expert from the Federal Ministry of Environment in Abuja as a potential cause of conflict. He stated:

"The Nigerian society is usually very accommodative towards persons in need. Many factors are however susceptible to destabilize the relationship between the person in need and the host. 


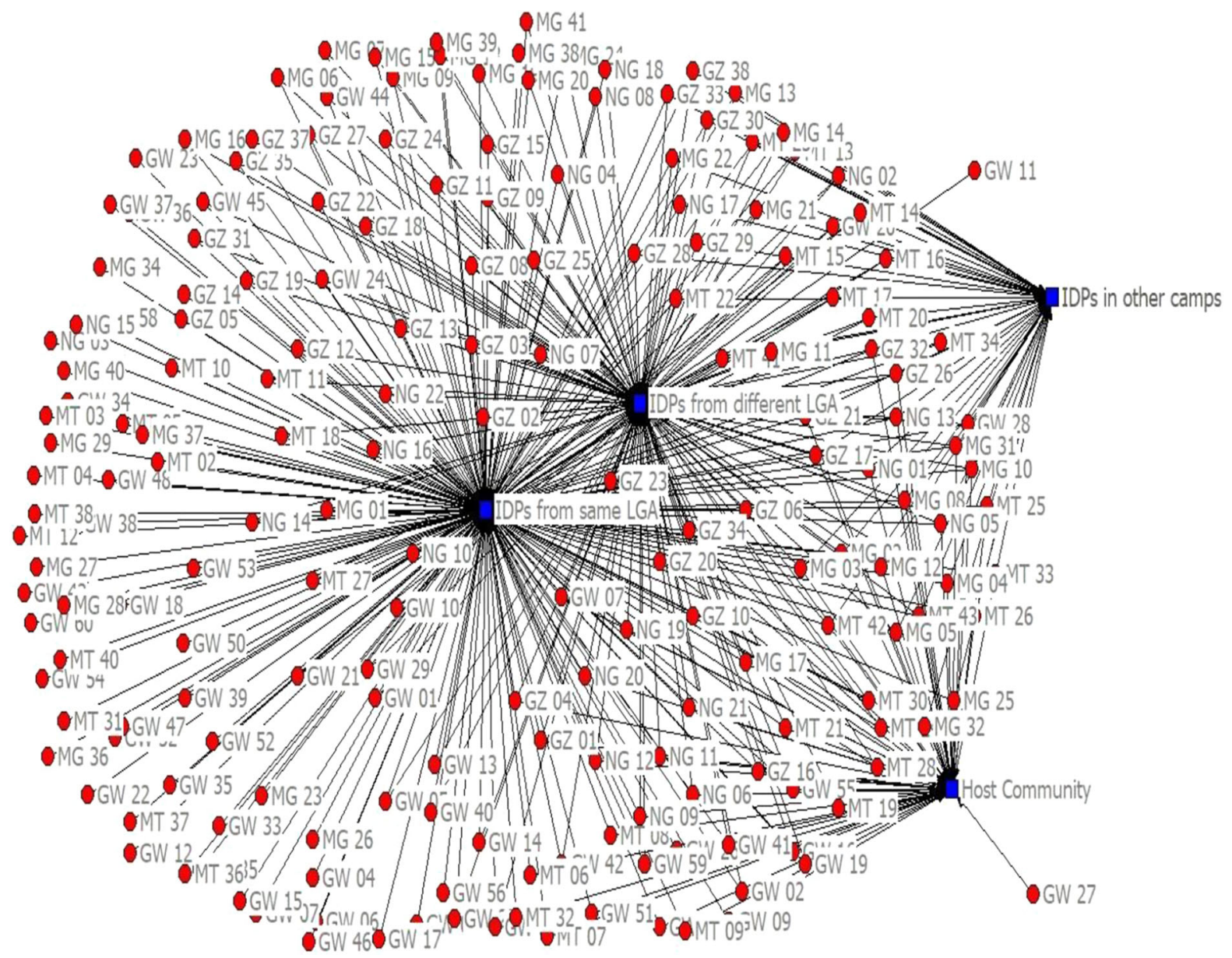

Fig. 4 Social network graph for friendly relationships among IDPs in the Bakassi IDP camp. The red dots represents IDPs as follows: GW01-GW60 represents IDPs from Gwoza, GZ01GZ38 represents IDPs from Guzamala, MT01-MT43 represents
IDPs from Marte, MG01-MG41 represents IDPs from Monguno, NG01-NG22 represents IDPs from Nganzai. The blue squared represents groups of IDPs and members of the host community. (Color figure online)

Table 4 Values of the betweenness centrality for friendly relationships within the Bakassi IDP camp

GW28, MT42,MT43,MG02, MG03,

0.001

MG04,MG05,MG08,MG10,

MG12,MG31,NG01,NG05,NG13,

GZ17,GZ21,GZ26,GZ32

Host community

0.033

IDPs in other camps

0.017

IDPs from same LGA

0.68

IDPs from different LGA

0.185

Such factors include the exhausting of the hosts' resources, the person in need requiring more resources in order to become independent, especially when such resources are limited in the host community". 


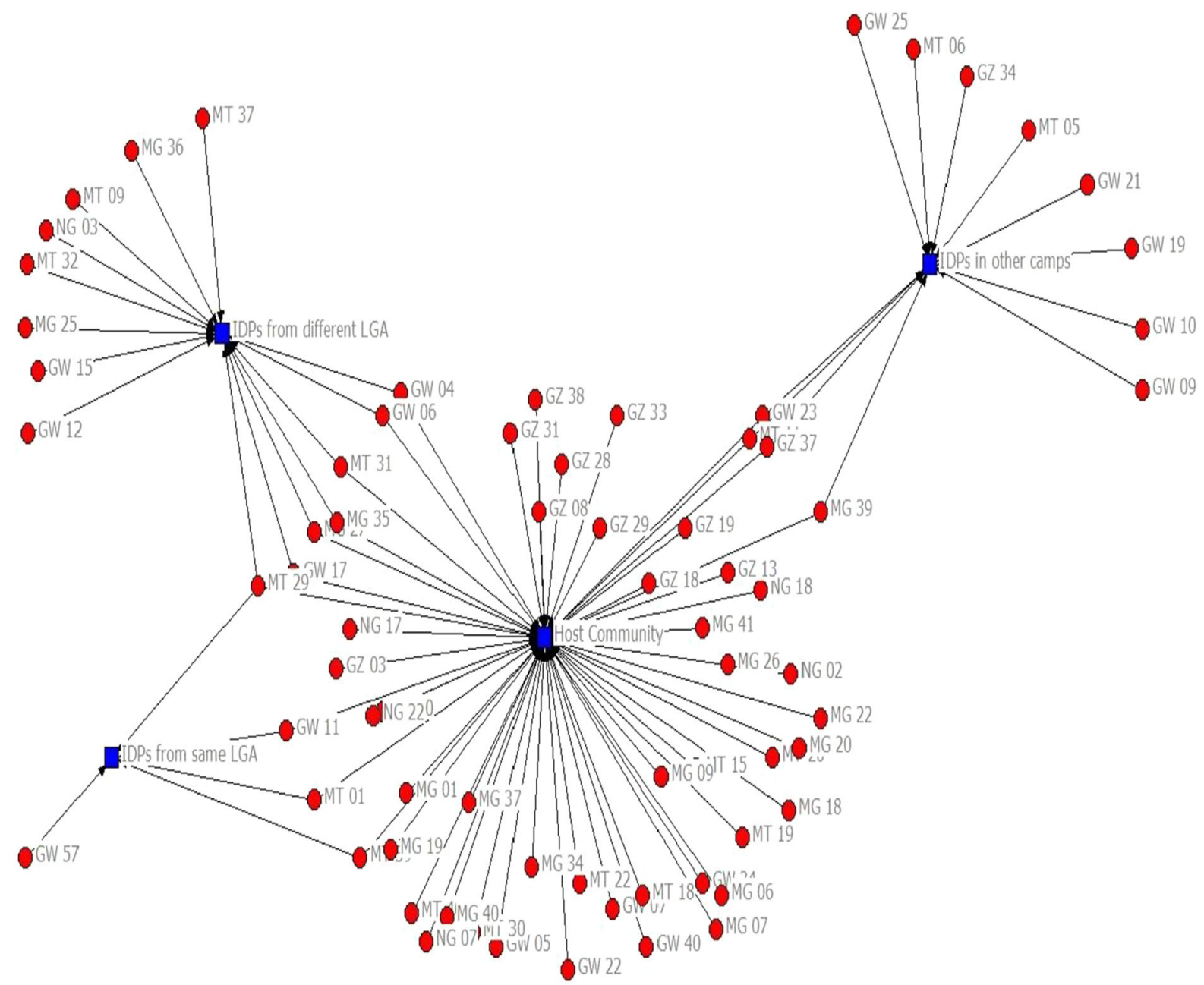

Fig. 5 Social network graph of conflicting relationships among IDPs at the Bakassi IDP camp. The red dots represents IDPs as follows: GW01-GW60 represents IDPs from Gwoza, GZ01GZ38 represents IDPs from Guzamala, MT01-MT43 represents IDPs from Marte, MG01-MG41 represents IDPs from
Monguno, NG01-NG22 represents IDPs from Nganzai. The blue squares represent IDPs in the Bakassi IDP camp, IDPs in other IDP camps and members of the host community. (Color figure online)
Table 5 Values of the betweenness centrality for conflicting relationships within the Bakassi IDP camp

\begin{tabular}{ll}
\hline Actors or groups of actors & Betweenness centrality \\
\hline GW11, MT01, MT39 & 0.002 \\
GW04, GW06, GW17, MT10, MT31, MG27, MG35, & 0.004 \\
MT29 & 0.007 \\
GW23, MT11, MG39, GZ37 & 0.009 \\
Local Community & 0.123 \\
IDPs in other camps & 0.027 \\
IDPs from same LGA & 0.004 \\
IDPs from different LGA & 0.028 \\
\hline
\end{tabular}


Results in the current study show a poor network connectivity in terms of friendly relationships between IDPs and members of the host community. Also, looking at the values of the betweenness centrality, only few IDPs showed a value of 0.001 and most IDPs did not show any value. This translates to the low connectivity between IDPs and members of the host community. Most problems usually encountered by IDPs in poor urban areas (such as Maiduguri) include difficulties securing a regular source of income. This is due to their lack of involvement in social networks, their dependence on state assistance and their difficulty in accessing formal and informal labor markets (Arredondo et al, 2011). Host communities securing the few available income opportunities (jobs and small businesses) by keeping close networks that exclude potential competitors such as IDPs may be seen as a plausible explanation to the low involvement of IDPs in social networks. According to experts at the National Emergency Management Agency (NEMA) interviewed in Abuja, the low involvement of IDPs in social networks may also be explained by the fact that they usually feel marginalized, and the perceived fear by host communities of being overshadowed by IDPs, given their growing numbers.

Increased climate vulnerability that manifests through unpredictable inter- and intra-annual rainfall patterns resulting in the deterioration of livelihood has contributed to damaging social cohesion, and fueled conflict between different social groups in northeast Nigeria (Vivekananda, 2018). Added to climate vulnerability that comes as a threat to IDPs is the fact that migrants in Nigeria are still seen as a threat multiplier rather than a constituent part of broader social and economic transformation processes (De Haas, 2007; Iwuoha, 2020). When interviewed on their feelings over the presence of IDPs in their community, most members of the host community usually expressed a negative opinion. A number of respondents in the host community made statements such as "the community was safer when IDPs were not around" or "we do not feel safe when we go outside our community". This was also confirmed by many IDPs when they were asked if they felt welcome by the host community. A 30 year-old woman from Gwoza said: "In the beginning, I felt welcomed, but now, not anymore" and a 35 year-old female from the same community, when asked the same questions replied "yes and no, it depends on the people I meet in the street".
The social networks analysis in the host community also confirm that members of the host community were not so keen to accept IDPs in their community. It appears that members of the host community were more connected to IDPs in camps far away from their community and only few connections were observed with IDPs at the Bakassi IDP camp that is closer to them. This may testify to the fact that the presence of IDPs in Maiduguri is seen by members of the host community as a threat multiplier. This may be due to the fact that IDPs are susceptible of excreting extra pressure on the very limited resources available to the host community.

Schilling et al. (2013) found that the potential of conflict can increase in the receiving area of migrants, especially if the migration is internal, forced and largescale. Such conditions are similar to those present in northeast Nigeria, where large numbers of IDPs migrated within Nigeria as a result of the insurgency of Boko Haram and the counter-insurgency by the state forces (see also IOM, 2016; Mukhtar et al., 2018; Mbiyozo, 2017; Kamta et al., 2020a). It is expected that Africa will most likely experience high impacts of climate change including water scarcity and food security (Niang et al., 2014), with the potential of aggravating conflict, instability and insecurity (Borderon et al., 2019; Scheffran et al., 2019). Such climate conditions and the resulting impact on the resources is expected to fuel conflicts in the Lake Chad Basin, hence increasing the number of displaced persons in the region (see Werz \& Conley, 2012; Akubor, 2017).

Efforts are made by the Nigerian authorities to limit contacts between IDPs and host communities in northeast Nigeria, and there is a perceived willingness of each group (IDPs on one side and host community members on the other side) to limit contacts. This may explain why a relatively peaceful atmosphere still reign as far as the IDP-host community relationship is concerned. Most experts interviewed believe however that it is only a matter of time until this relationship becomes conflicting. In other parts of Nigeria such as Jos and Kaduna, the incoming of internal migrants has resulted in ethno-religious conflict with the host community (Werz \& Conley, 2012). The numbers of IDPs in northeast Nigeria has continued to rise but the amount of services provided, such as food, shelter and healthcare, has remained unimproved (Letswa \& Isyaku, 2018). It can therefore be predicted that if nothing is done to improve services provided to IDPs 
and to stop or reduce new arrivals, camps will no longer be able to contain them, and contacts with the host community tend to increase with the potential of creating new tensions.

\section{Conclusion}

The aim of this study was to determine the social networks in which IDPs are involved in Maiduguri, as well as the potential of conflict between IDPs and host communities in close proximity of the Bakassi IDP camp in Maiduguri. Results show that the relationship between IDPs in the IDP camp were usually friendly and there were an increase of conflicting relationships between IDPs and members of the host community. Members of the host community interestingly had only few connections with IDPs in the Bakassi camp located in their community, while most of them were connected to IDPs in other camps far away from their community. This behavior was seen in this study as a way for members of the host community to exclude IDPs from the community's resources such land, water, jobs or economic opportunities, as IDPs are considered to be competitors for these resources.

Most IDPs interviewed in this study migrated to Maiduguri in search of safety, after being subjected to the insecurity created by the insurgency of Boko Haram, and the counter insurgency by the government. Many indicated that the choice of Maiduguri as a destination was partially motivated by the presence of a relative who could host them. Members of the host community also indicated having relatives at the Bakassi IDP camp or in other camps in Maiduguri. It can be assumed that because of these affinities between IDPs and the host community, the relationship will remain peaceful. Social network data presented in this study show something different. Few IDPs reported having a friendly relationship with members of the host community, while many of them had conflicting relationships with members of the host community. On the other hand, members of the host community reported having limited contacts with IDPs and relatives living in the IDP camp. The previous finding suggested that the relationship between IDPs and their host community in Maiduguri were not of a very good nature. Experts interviewed in this study also believe that even though the relationship between IDPs and the host community may seem peaceful for now, these relationships may change to become conflicting over time. Experts identified resource scarcity and lack of economic opportunities as possible factors that may cause tensions between IDPs and their host communities in Maiduguri.

Field experts interviewed in the National Emergency Management Agency (NEMA) also identified service delivery to IDPs in northeast Nigeria as a potential cause of tensions between IDPs and host communities. Members of the host community that also have basic needs feel that they should be treated the same way IDPs are treated. This study recommends that while service delivery to IDPs should be improved, host communities should also be taken into account with basic commodities. The social network presented in this study may allow to identify key actors that can be useful for peacekeeping between IDPs and host community. Those are actors with high betweenness centrality in terms of friendly relationships. On the other hand, actors with high betweenness centrality in terms of conflicting relationships can be identified and restricted from contacts with the host community for peace keeping.

Authors' contributions Project design: FNK and JS; data collection, analysis and curation: FNK; writing - original draft preparation: FNK; writing - review and editing: JS.

Funding Open Access funding enabled and organized by Projekt DEAL. This research was funded by the German Academic Exchange Service-DAAD, and the Universität Hamburg's Cluster of Excellence 'Climate, Climatic Change and Society-CLICCS', funded by the German Research Foundation DFG.

Availability of data and materials Not applicable.

Code availability Not applicable.

\section{Declarations}

Conflict of interest The authors declare no conflict of interest.

Open Access This article is licensed under a Creative Commons Attribution 4.0 International License, which permits use, sharing, adaptation, distribution and reproduction in any medium or format, as long as you give appropriate credit to the original author(s) and the source, provide a link to the Creative Commons licence, and indicate if changes were made. The images or other third party material in this article are included in the article's Creative Commons licence, unless indicated otherwise in a credit line to the material. If material is not included in the article's Creative Commons licence and your 
intended use is not permitted by statutory regulation or exceeds the permitted use, you will need to obtain permission directly from the copyright holder. To view a copy of this licence, visit http://creativecommons.org/licenses/by/4.0/.

\section{References}

Adeola, R. (2020). Protecting conflict-induced displacees in northern Nigeria: Assessing the compliance of the state with Article 9(2) of the Kampala convention. In W. L. Filho (Ed.), Handbook of climate change resilience. Cham: Springer.

Akubor, E. O. (2017). Climate change, migration and conflict: A historical survey of people of northern Nigeria and their neighbors from the period of the Mega Chad. Localities, 7 , (9), 9-41.

Alonso, W. (1986). Systemic and log-linear models: From here to there, then to now, and this to that. Center for Population Studies, Harvard University.

Antwi-Boateng, O. (2017). The rise of pan-Islamic terrorism in Africa: A global security challenge. Politics \& Policy, 45(2), 253-284. https://doi.org/10.1111/polp.12195

Arredondo, C. A., Salcedo, J., \& López, R. C. V. (2011). The effects of internal displacement on host communities. https://www.brookings.edu/research/the-effects-ofinternal-displacement-on-host-communities/. Accessed 10 August 2020.

Beck, D. C., Choi, R. R., Munro-Kramer, M. L., \& Lori, J. R. (2017). Human trafficking in Ethiopia: A scoping review to identify gaps in service delivery, research, and policy. Trauma, Violence \& Abuse, 18(5), 532-543. https://doi. org/10.1177/1524838016641670

Beltramo, T., \& Rossiasco, P. A. (2016). Forced displacement by the Boko Haram conflict in the Lake Chad region. The UNHCR and the World Bank Group.

Bodin, E. O., \& Prell, C. (2011). Social networks and natural resource management: Uncovering the Social Fabric of Environmental Governance. Cambridge University Press.

Borderon, M., Sakdapolrak, P., Muttarak, R., Kebede, E., Pagogna, R., \& Sporer, E. (2019). Migration influenced by environmental change in Africa: A systematic review of empirical evidence. Demographic Research, 41(18), 491-544. https://doi.org/10.4054/DemRes.2019.41.18

Borgatti, S. P. (2002). Netdraw network visualization. Analytic Technologies.

Borgatti, S. P. (2005). Centrality and network flow. Social Networks, 27 (1), 55-71. https://doi.org/10.1016/j.socnet. 2004.11.008

Borgatti, S. P. (2009). 2-Mode concepts in social network analysis. University of Kentucky.

Borgatti, S. P., Everett, M. G., \& Freeman, L. C. (2002). Ucinet 6 for Windows: Software for social network analysis. Analytic Technologies.

Boustan, L. P., Fishback, P. V., \& Kantor, S. (2010). The effect of internal migration on local labor markets: American cities during the Great Depression. Journal of Labor Economics, 20(4), 719-746.
Brandes, U. (2001). A faster algorithm for betweenness centrality. Journal of Mathematical Sociology, 25(2), 163-177.

Bukari, K. N., Bukari, S., Sow, P., \& Scheffran, J. (2020). Diversity and multiple drivers of pastoral Fulani migration to Ghana. Nomadic Peoples, 24(2020), 4-31.

Davies, A. (2012). IDPs in host families and host communities: Assistance for hosting arrangements. United Nations High Commissioner for Refugees.

De Haas, H. (2007). The myth of invasion: Irregular migration from West Africa to the Maghreb and the European Union. University of Oxford.

Egger, E.-M. (2017). Causes and consequences of internal migration: Evidence from Brazil and Ghana. University of Sussex.

European Asylum Support Office (EASO). (2016). The push and pull factors of Asylum-related migration. Publications Office of the European Union.

Flavell, A., Milan, A., \& Melde, S. (2020). Migration, environment and climate change: Literature review. German Environment Agency.

Freeman, L. C. (1979). Centrality in social networks: Conceptual clarification. Social Networks, 1, 215-239.

Freeman, L. (2017). Environmental change, migration, and conflict in Africa: A critical examination of the interconnections. Journal of Environment \& Development, 26(4), 351-374.

Gatewood, J. R., \& Price, C. R. (2017). Utilizing social network analysis to study communities of women in conflict zones. Journal of Humanistic Mathematics, 7(1), 3-21. https:// doi.org/10.5642/jhummath.201701.03

Gemenne, F., \& Reuchlin, P. (2008). Climate change and displacement: Central Asia case study 31. https://www. fmreview.org/sites/fmr/files/FMRdownloads/en/ climatechange/gemenne-reuchlin.pdf. Accessed 18 March 2021.

Giménez-Gómez, J.-M., Walle, Y. M., \& Zewdu-Zergawu, Y. (2019). Trends in African migration to Europe: Drivers beyond economic motivations. Journal of Conflict Resolution, 63(8), 1797-1831. https://doi.org/10.1177/ 0022002718823907

Guéhenno, J.-M. (2016). Conflict is key to understanding migration. https://carnegieeurope.eu/strategiceurope/?fa= 63578. Accessed 18 March 2021.

Havig, P. R., McIntire, J. P., Geiselman, E., \& Mohd-Zaid, F. (2012). Why social network analysis is important to Air Force applications. Berlin: The Air Force Research Laboratory.

Holobinko, A. (2012). Theoretical and methodological approaches to understanding human migration patterns and their utility in forensic human identification cases. Societies. https://doi.org/10.3390/soc2020042

International Organization for Migration (IOM). (2015). IOM highlights need for regional response to Boko Haram displacement. https://www.iom.int/news/iom-highlightsneed-regional-response-boko-haram-displacement. Accessed 7 August 2020.

International Organization for Migration (IOM). (2016). Within and beyond borders: Tracking displacement in the Lake Chad Basin. The International Organization for Migration, Regional Office for West and Central Africa. 
Iwuoha, V. C. (2020). Street-hawking in a Foreign Land: Social dynamics of migrant petty traders' livelihoods in Nigeria. Journal of Asian and African Studies. https://doi.org/10. 1177/0021909620916912

Jacob, J. U. U., Abia-Bassey, M., Nkanga, E., \& Aliyu, A. (2016). Narratives of displacement: Conversations with Boko Haram displaced persons in northeast Nigeria. Contemporary French and Francophone Studies, 20(2), 176-190. https://doi.org/10.1080/17409292.2016.1144324

Jeong, H. W. (2000). Peace and conflict studies: An introduction. Ashgate Publishing.

Kamta, F. N., Hossein, A., \& Scheffran, J. (2020a). The root causes of the crisis in Northeast Nigeria: Historical, socioeconomic and environmental dimensions. Mediterranean Journal of Social Sciences, 11(3), 95-104. https:// doi.org/10.36941/mjss-2020-0033

Kamta, F. N., Schilling, J., \& Scheffran, J. (2020b). Insecurity, resource scarcity, and migration to camps of internally displaced persons in northeast Nigeria. Sustainability, 12(6830), 1-15. https://doi.org/10.3390/su12176830

Kleemans, M., \& Magruder, J. (2017). Labor market changes in response to immigration: Evidence from internal migration driven by weather shocks. The Economic Journal, 128(613), 2032-2065.

Kniveton, D. R., Smith, C. D., \& Black, R. (2012). Emerging migration flows in a changing climate in Dryland Africa. Nature Climate Change, 2(6), 444-447.

Ladan, M. T. (2004). Migration, trafficking, human rights and refugees under international law: A case study of Africa. Ahmadu Bello University Press Limited.

Letswa, A. M., \& Isyaku, S. S. (2018). Insurgency and internally displaced persons IDPs in Nigeria: a reflection on the causes, implication and way forward. International Journal of Innovative Studies in Sociology and Humanities, 3(5), 36-48.

Lucassen, J., Lucassen, L., \& Manning, P. (2010). Migration history: Multidisciplinary approaches. In J. Lucassen, L. Lucassen, \& P. Manning (Eds.), Migration history in world history: Multidisciplinary approaches. Koninklijke Brill NV.

Mbiyozo, A.-N. (2017). How Boko Haram specifically targets displaced people. Institute for Security Studies.

McAuliffe, M., Kitimbo, A., Abel, G., Sawye, A., \& Klatt, J. (2019). Migration and migrants: Regional dimensions and developments. In M. McAuliff \& B. Khadri (Eds.), World Migration Report 2020.

McNeill, W. H. (1984). Human migration in historical perspective. Population and Development Review, 10(1), 1-18. https://doi.org/10.2307/1973159

Mertens, F., Fillion, M., Saint-Charles, J., Mongeau, P., Távora, R., Passos, C. J. S., \& Mergler, D. (2015). The role of strong-tie social networks in mediating food security of fish resources by a traditional riverine community in the Brazilian Amazon. Ecology and Society, 20(3), 18. https:// doi.org/10.5751/ES-07483-200318

Mincer, M., \& Niewiadomska-Szynkiewicz, E. (2012). Application of social network analysis to the investigation of interpersonal connections. Journal of Telecommunications and Information Technology, 2, 81-89.
Mitchell, M. I. (2018). Migration, sons of the soil conflict, and international relations. International Area Studies Review, 21(1), 51-67. https://doi.org/10.1177/2233865917745417

Mukhtar, S., Rose, R. A. C., Choy, L. K., \& Bibi-Farouk, U. I. (2018). Boko Haram and the geopolitics of forced migration in Nigeria. Journal of International Studies, 14, 51-63.

Ngaruiya, G. W., \& Scheffran, J. (2016). Actors and networks in resource conflict resolution under climate change in rural Kenya. Earth System Dynamics, 7(2), 441-452. https://doi. org/10.5194/esd-7-441-2016

Niang, I., Ruppel, O. C., Abdrabo, M. A., Essel, A., Lennard, C., Padgham, J., \& Urquhart, P. (2014). Part B: Regional aspects. Contribution of Working Group II to the fifth assessment report of the Intergovernmental Panel on Climate Change. In V. R. Barros, C. B. Field, D. J. Dokken, M. D. Mastrandrea, K. J. Mach, T. E. Bilir, M. Chatterjee, K. L. Ebi, Y. O. Estrada, R. C. Genova, B. Girma, E. S. Kissel, A. N. Levy, S. MacCracken, P. S. Mastrandrea, \& L. L. White (Eds.), Climate change 2014 (pp. 1199-1265). Cambridge University.

Obi-Ani, N. A., \& Osiani, M. C. (2020). Urbanization in Nigeria: The Onitsha experience. Cities, 104(102744), 1-14. https://doi.org/10.1016/j.cities.2020.102744

Organization for Economic Co-operation and Development (OECD). (2016). Why is migration increasing in the Americas. Organization for Economic Co-operation and Development (OECD).

Oyedeji, B. (2017). Managing tribalism within Nigeria's democratic challenges. Modern Applied Science, 11(11), 49-59. https://doi.org/10.5539/mas.v11n11p49

Philip, L. J. (1997). Combining quantitative and qualitative approaches to social research in human geography-An impossible mixture? Environment and Planning, 30(2), 261-276.

Piguet, E. (2012). The drivers of human migration. Nature Climate Change, 2, 400.

Ravenstein, E. G. (1889). The laws of migration. Journal of the Royal Statistical Society, 48(2), 167-227.

Rudincová, K. (2017). Desiccation of Lake Chad as a cause of security instability in the Sahel region. GeoScape, 11(2), 112-120. https://doi.org/10.1515/geosc-2017-0009

Scheffran, J. (2020). The geopolitical impact of climate change in the Mediterranean region: Climate change as a trigger of conflict and migration. In Mediterranean Yearbook 2020: IEMed.

Scheffran, J., Link, P. M., \& Schilling, J. (2019). Climate and conflict in Africa. Oxford Research Encyclopedia of Climate Science. https://doi.org/10.1093/acrefore/ 9780190228620.013 .557

Scheffran, J., Marmer, E., \& Sow, P. (2012). Migration as a contribution to resilience and innovation in climate adaptation: Social networks and co-development in West Africa. Applied Geography, 33, 119-127.

Schelling, T. (1978). Macromotives and macrobehavious. Norton.

Schilling, J., Vivekananda, J., Khan, M. A., \& Pandey, M. (2013). Vulnerability to environmental risks and effects on community resilience in Mid-West Nepal and South-East Pakistan. Environment and Natural Resources Research, 3(4), 27-45. https://doi.org/10.5539/enrr.v3n4p27 
Smith, L. R. (2013). Female refugee networks: Rebuilding postconflict identity. International Journal of Intercultural Relations, 37(1), 11-27.

Sow, P., Adaawen, S. A., \& Scheffran, J. (2014). Migration, social demands and environmental change amongst the Frafra of Northern Ghana and the Biali in Northern Benin. Sustainability, 6(1), 375-398. https://doi.org/10.3390/ su6010375

Sow, P., Marmer, E., \& Scheffran, J. (2015). Between the heat and the hardships. Climate change and mixed migration flows in Morocco. Migration and Development. https://doi. org/10.1080/21632324.2015.1022968

Sridevi, S., \& Arun, B. R. K. (2015). Social network analysis and its applications-A review from business perspective. International Journal of Informative \& Futuristic Research, 2(9), 3006-3013.

Thakore, D. (2013). Conflict and conflict management. Journal of Business and Management, 8(6), 7-16.

Tjosvold, D. (2006). Defining conflict and making choices about its management lighting the dark side of organizational life. International Journal of Conflict Management, 17(2), 87-95. https://doi.org/10.1108/10444060610736585

United Nations General Assembly (UNGA). (1951). Convention and protocol relating to the status of refugees.

United Nations High Commissioner for Refugees (UNHCR). (1998). Guiding principles on internal displacement.

Vivekananda, J. (2018). Climate change, conflict and crisis in Lake Chad. Great Insights magazine. https://ecdpm.org/ great-insights/complex-link-climate-change-conflict/ climate-change-conflict-crisis-lake-chad/. Accessed 10 January 2021.

Warner, K., \& Afifi, T. (2014). Where the rain falls: Evidence from 8 countries on how vulnerable households use migration to manage the risk of rainfall variability and food insecurity. Climate and Development, 6(1), 1-17.

Wasserman, S., \& Faust, K. (1994). Social network analysis methods and applications. Cambridge University Press.

Weiner, M. (1992/1993). Security, stability and international migration. International Security, 17(3), 91-126. https:// doi.org/10.2307/2539131

Werz, M., Conley, L. (2012). Climate change, migration, and conflict in northwest Africa. Center for American Progress; Henrich Böll Stiftung.

World Population Review (WPR). (2021). Maiduguri population 2021. https://worldpopulationreview.com/worldcities/maiduguri-population. Accessed 11 July 2021.

Zieba, F. W., Yengoh, G. T., \& Tom, A. (2017). Seasonal migration and settlement around Lake Chad: Strategies for control of resources in an increasingly drying lake. $R e$ sources, 6(41), 1-16. https://doi.org/10.3390/ resources6030041

Publisher's Note Springer Nature remains neutral with regard to jurisdictional claims in published maps and institutional affiliations. 